\title{
Are Alexithymia, Depression and Hostility Related?
}

\author{
Balta GT, Karachalios T, Tsikrikas T, Angelopoulos NV
}

\begin{abstract}
Background: Depression correlates positively with alexithymia. Less is known about the relationship between hostility and depression and even less about hostility and alexithymia. The aim of this study is to examine the relationship between alexithymia, hostility and depression.

Methods: The study was carried out with 308 subjects: 102 patients suffering from somatic illnesses, 98 depressive patients and 108 healthy people. The mean age of the group was $\mathbf{4 0 . 2 6}$ years (sd=11.63); 184 of them were women and 124 were men. The participants were assessed with the Beck Depression Index (BDI-21), the 20-item Toronto Alexithymia Scale (TAS-20), the Hostility and Direction of Hostility Scale (HDHQ). Data regarding sociodemographic characteristics were also collected. Linear regression was performed to evaluate the relationship between the scores of the participants in each scale.

Results: Alexithymia scores correlate positively with depression scores $(\alpha=41.73$ and $B=0.88, p=.000)$. Hostility scores correlate positively with depression scores $(\alpha=15.66$ and $\mathrm{B}=\mathbf{0 . 3 9}, \mathrm{p}=\mathbf{. 0 0 0})$. Finally, alexithymia scores correlate positively with hostility scores $(\alpha=31.05$ and $B=1.05, p=.000)$.

Conclusions: The more depressive somebody is, the more alexithymic and hostile he is likely to be; finally, the more hostile someone is, the more alexithymic he is likely to be.
\end{abstract}

Index Terms - Alexithymia, Depression, Hostility.

\section{INTRODUCTION}

The term "alexithymia" has greek origin. It was first coined by Sifneos in 1972 [1] and means "no words for feeling". Alexithymia is a multidimensional construct, a syndrome manifesting affective, cognitive, and perceptual defects. The primary characteristics of alexithymia include difficulty identifying and describing feelings; difficulty differentiating between emotional states and physical sensations; constricted imaginative activity, as evidenced by a paucity of fantasies and dreams; and a concrete, externally oriented cognitive style [2] - [4]. Although initially described in the context of psychosomatic illness, alexithymic characteristics may be observed in patients with a wide range of medical and psychiatric disorders, as well as in the general population [5].

Hostility, one of the most distinctive epiphenomena of frustrating conditions, is valuable in psychiatric research and clinical practise, because, by being an attitude rather than a personality trait [6], it is changeable under the influence of

Georgia T. Balta, M.D, Ph. D, University of Thessaly, Medical School, Department of Psychiatry, Biopolis, Larissa, Greece.

Karachalios Theophilos, Professor of Orphopaedics, Othopaedic Department, University of Thessaly, Medical School, Biopolis, Larissa, Greece.

Tsikrikas Thomas, Assistant Professor of Internal Medicine University of Thessaly, Medical School, Biopolis, Larissa, Greece.

Nikiforos V. Angelopoulos, Professor of Psychiatry, University of Thessaly, Medical School, Department of Psychiatry, Biopolis, Larissa, Greece. external events or during the course of symptoms, psychiatric or somatic. Hence, its assessment could contribute to the elucidation of the relationships between personality, psychiatric symptoms and illness in medical and psychiatric patients [7]. Less studies have been concerned about the relationship between hostility and depression, and even lees are known about the possible connection between alexithymia and hostility. No studies were found to study the relationship between hostility, depression and alexithymia. The aim of the present study was to gain a better insight into these structures and its relationship.

\section{SUBJECTS AND METHODS}

The study utilized data from 308 people: 102 somatic patients, 98 depressive patients and 108 healthy people.

a) Somatic patients were hosted in the General Hospital of Karditsa. Among them, 55 suffered from acute somatic illnesses (pneumonia, influenza, gastroenderitis), and 47 of them suffered from chronic somatic illnesses (hypertension, diabetes, anemia, hepatitis B). All somatic patients were not on cortisone, alcohol or other psychotropic drugs, neither had their somatic disease impaired their cognitive functions.

b) Depressive patients were attended in the Psychiatric department of the Universital Hospital of Larissa. They were all on anti-depressive medication and frequent psychiatric consultation. None of them had cognitive impairment, nor had they suicidal ideation or psychotic symptoms; and they were not on cortisone or alcohol.

c) Healthy subjects were employees of the General Hospital of Karditsa. They were randomly selected from the hospital's staff-list and they were matched by sex and age. They were not manifesting problems requiring medical or psychiatric intervention and were free of any medication at the time of investigation, nor had they a history of psychiatric illness, current alcohol or/and drug abuse or dementia.

\section{TOOLS}

The participants were assessed with the following questionnaires: 1) The Beck Depression Index (BDI-21), in order to estimate their depression. 2) The Toronto Alexithymia Scale (TAS-20), to measure the alexithymia of the subjects. 3) The Hostility and Direction of Hostility Questionnaire (HDHQ), so that hostility of the sample was estimated.

Beck Depression Index (BDI-21). The Beck Depression Index [8], [9] estimates the cognitive, emotional, behavioral and somatic signs of depression during the last week. It comprises of 21 questions, each of which is graded from 0 to 3 , according to its gravity. The themes mentioned concern grief, pessimism, feeling failed, anedonia, guilt, waiting to be punished, self-disgust, self-reproof, suicidal thoughts, crying, hyperexcitability, social retraction, indecision, body image, 
work capacity, weight loss, lost of libido. The total score comes as the sum of the scores of each one of the 21 questions. The scale was translated and adjusted for Greek population by Donias and Demertzis [10], [11].

Toronto Alexithymia Scale (TAS-20). The Torondo Alexithymia Scale was created by Bagby, Taylor and Parker [12] - [16], in order to measure alexithymia. It is a self-report questionnaire, consisting of 20 questions divided in 3 subscales: i)F1. It estimates the difficulty in identifying feelings. ii)F2. It measures the difficulty in describing feelings. iii)F3. It studies externally oriented thinking. Each question is scored from 1 to 5 and the total score TAS-S is the sum of the 3 subscale scores. High scores indicate an inability to identify and describe one's emotions, as well as an impairment in mentalizing emotional experience. TAS has been proven to be reliable and valid with a Cronbach's a for subscale A of 0.78 , for subscale B 0.68 , for subscale C 0.60 , while Cronbach's a for the total scale is 0.80 . The Greek version of the scale, adjusted in Greek by Anagnostopoulou and G. Kioseoglou, has been validated in a cohort of Greek students by Tsaousis et al [17].

Hostility and Direction of Hostility Questionnaire (HDHQ). HDHQ [18] estimates hostility more as an attitude and a way of thinking, rather than a physical reaction. It is an attitudinal measure for a wide range of hostility manifestations, minimally reflecting physically expressed aggressive behavior. Two dimensions underlie hostility as it is measured by the HDHQ: a readiness to respond with aggressive behavior and a tendency to evaluate persons, including the self, in negative terms. It consists of 5 subscales of 52 items. Three subscales, Acting out Hostility AH, Criticism of Others $\mathrm{CO}$ and Paranoid Hostility PH, are measures of Extraverted Hostility or Extrapunitiveness TE. Two subscales, Self Criticism SC and Guilt G, are measures of Introverted Hostility or Intropunitiveness TI. Total Hostility TH comes as the sum of TE and TI. Direction of Hostility Score DHS indicates the way total hostility is directed; inside oneself (positive scores) and outside oneself (negative scores) and is calculated by the form: $\mathrm{AH}+\mathrm{CO}+\mathrm{PH}-2 \mathrm{SC}-\mathrm{G}$. The accepted score norms for total hostility in normal populations are between 12-14, but higher norms have also been suggested [19]. The HDHQ has not yet been standardized in Greek populations, but it has been used in Greek normals [20] and psychiatric [21](Lyketsos et al, 1988) or somatic patients [7], [22].

Data were collected from the questionnaires and processed with the Statistical Package for Social Science SPSS (version 10,0) [23]. Linear regression was performed to evaluate the relationship between the scores of the participants in each scale.

\section{RESULTS}

The group consisted of 308 people. The mean age of the group was 40.26 years $(s d=11.63, \min =18, \max =60), 124$ of them were male $(40.3 \%)$ and 184 female $(59.7 \%), 128$ were single (41.6\%), 157 married (51\%), 8 were widows $(2.6 \%)$ and 15 divorced $(4.9 \%)$.

Linear regression showed that there was positive correlation between alexithymia and depression scores, between hostility and depression scores and between hostility and alexithymia scores. The results are shown in table 1 .

Table 1. Correlations between alexithymia scores, depression scores and hostility scores.

(Alexithymia scores $=$ TAS-S, F1, F2, F3. Depresion scores= BDI. Hostility scores $=$ AH, CO, PH, SC, G, TE, TI, TH.)

\begin{tabular}{|c|c|c|c|c|c|}
\hline & BDI & TAS-S & F1 & F2 & F3 \\
\hline TAS-S & $\begin{array}{l}\alpha= \\
41.73 \\
\text { and } B= \\
0.88, \\
p=.000\end{array}$ & & & & \\
\hline F1 & $\begin{array}{l}\alpha= \\
12.44 \\
\text { and } \mathrm{B}= \\
0.49, \\
\mathrm{p}=.000\end{array}$ & & & & \\
\hline F2 & $\begin{array}{l}\alpha= \\
11.37 \\
\text { and } B= \\
0.10, \\
p=.000\end{array}$ & & & & \\
\hline F3 & $\begin{array}{l}\alpha= \\
18.06 \\
\text { and } B= \\
0.28, \\
p=.000\end{array}$ & & & & \\
\hline $\mathbf{A H}$ & NS & $\begin{array}{l}\alpha= \\
43.37 \\
\text { and } B= \\
1.95, p= \\
.000\end{array}$ & $\begin{array}{l}\alpha= \\
14.07 \\
\text { and } B= \\
0.95, \\
p=.000\end{array}$ & $\begin{array}{l}\alpha=9.91 \\
\text { and } B= \\
0.58 \\
p=.000\end{array}$ & $\begin{array}{l}\alpha= \\
19.78 \\
\text { and } B= \\
0.35, \\
p=.014\end{array}$ \\
\hline $\mathrm{CO}$ & NS & $\begin{array}{l}\alpha= \\
38.27 \\
\text { and } \mathrm{B}= \\
2.34, \mathrm{p}= \\
.000\end{array}$ & $\begin{array}{l}\alpha= \\
11.78 \\
\text { and } \mathrm{B}= \\
1.10, \\
\mathrm{p}=.000\end{array}$ & $\begin{array}{l}\alpha=8.68 \\
\text { and } B= \\
0.61, \\
p=.000\end{array}$ & $\begin{array}{l}\alpha= \\
18.18 \\
\text { and } \mathrm{B}= \\
0.54, \\
\mathrm{p}=.000\end{array}$ \\
\hline $\mathbf{P H}$ & NS & $\begin{array}{l}\alpha= \\
44.49 \\
\text { and } \mathrm{B}= \\
2.99, \mathrm{p}= \\
.000\end{array}$ & $\begin{array}{l}\alpha= \\
14.07 \\
\text { and } B= \\
1.65, \\
p=.000\end{array}$ & $\begin{array}{l}\alpha= \\
10.98 \\
\text { and } \mathrm{B}= \\
0.68 \\
\mathrm{p}=.000\end{array}$ & $\begin{array}{l}\alpha= \\
19.69 \\
\text { and } B= \\
0.65, \\
p=.000\end{array}$ \\
\hline SC & $\begin{array}{l}\alpha=2.54 \\
\text { and } B= \\
0.15, \\
p=.000\end{array}$ & $\begin{array}{l}\alpha= \\
37.85 \\
\text { and } B= \\
3.33, p= \\
.000\end{array}$ & $\begin{array}{l}\alpha= \\
10.51 \\
\text { and } \mathrm{B}= \\
1.81, \\
\mathrm{p}=.000\end{array}$ & $\begin{array}{l}\alpha=9.92 \\
\text { and } B= \\
0.62, \\
p=.000\end{array}$ & $\begin{array}{l}\alpha= \\
17.48 \\
\text { and } \mathrm{B}= \\
0.89, \\
\mathrm{p}=.000\end{array}$ \\
\hline $\mathbf{G}$ & $\begin{array}{l}\alpha=1.15 \\
\text { and } B= \\
0.13, \\
p=.000\end{array}$ & $\begin{array}{l}\alpha= \\
40.65 \\
\text { and } B= \\
4.38, p= \\
.000\end{array}$ & $\begin{array}{l}\alpha= \\
11.90 \\
\text { and } B= \\
2.43, \\
p=.000\end{array}$ & $\begin{array}{l}\alpha= \\
10.65 \\
\text { and } B= \\
0.73, \\
p=.000\end{array}$ & $\begin{array}{l}\alpha= \\
18.22 \\
\text { and } \mathrm{B}= \\
0.19, \\
\mathrm{p}=.000\end{array}$ \\
\hline
\end{tabular}




\begin{tabular}{|c|c|c|c|c|c|}
\hline TE & $\begin{array}{l}\alpha= \\
12.02 \\
\text { and } B= \\
0.12, \\
p=.000\end{array}$ & $\begin{array}{l}\alpha= \\
36.82 \\
\text { and } B= \\
1.17, p= \\
.000\end{array}$ & $\begin{array}{l}\alpha= \\
10.57 \\
\text { and } B= \\
0.58, \\
p=.000\end{array}$ & $\begin{array}{l}\alpha=8.59 \\
\text { and } B= \\
0.30 \\
p=.000\end{array}$ & $\begin{array}{l}\alpha= \\
18.21 \\
\text { and } B= \\
0.24, \\
p=.000\end{array}$ \\
\hline TI & $\begin{array}{l}\alpha=3.68 \\
\text { and } B= \\
0.28, \\
p=.000\end{array}$ & $\begin{array}{l}\alpha= \\
37.36 \\
\text { and } B= \\
2.13, p= \\
.000\end{array}$ & $\begin{array}{l}\alpha= \\
10.18 \\
\text { and } \mathrm{B}= \\
1.16, \\
\mathrm{p}=.000\end{array}$ & $\begin{array}{l}\alpha=9.93 \\
\text { and } B= \\
0.38, \\
p=.000\end{array}$ & $\begin{array}{l}\alpha= \\
17.39 \\
\text { and } \mathrm{B}= \\
0.57, \\
\mathrm{p}=.000\end{array}$ \\
\hline TH & $\begin{array}{l}\alpha= \\
15.66 \\
\text { and } B= \\
0.39 \\
p=.000\end{array}$ & $\begin{array}{l}\alpha= \\
31.05 \\
\text { and } B= \\
1.05, p= \\
.000\end{array}$ & $\begin{array}{l}\alpha=7.11 \\
\text { and } B= \\
0.56, \\
p=.000\end{array}$ & $\begin{array}{l}\alpha=7.98 \\
\text { and } B= \\
0.23, \\
p=.000\end{array}$ & $\begin{array}{l}\alpha= \\
16.43 \\
\text { and } B= \\
0.25, \\
p=.000\end{array}$ \\
\hline
\end{tabular}

\section{DISCUSSION}

The results of this study propose that alexithymia scores correlate positively with depression scores, hostility scores correlate positively with depression scores, and hostility scores correlate positively with alexithymia scores. In others words, the more depressive somebody is, the more alexithymic he is likely to be; the more depressive someone is, the more hostile he is likely to be; and the more alexithymic somebody is, the more hostile he is likely to be.

The association between alexithymic features and depression is quite an interesting topic.

A great number of studies accepted alexithymia to be strongly related to depression [24] - [28] considering it to be a state phenomenon. Honkalampi et al [29], in a 12-month follow-up study in a sample of 1584 people from Eastern Finland, suggested that alexithymic features appear to be strongly related to depressive symptoms. Gunzelmann et al [30] investigated alexithymia in random population sample of 566 people over 60 years of age. The results of their study also confirmed the assumption that there is connection between alexithymia and depression. In our study, we tested the relationship between alexithymia and depression in a sample of 308 people. Among them, some suffered from major depression, some from somatic illnesses and some appeared to be physically and mentally healthy. Studing this population, we found that alexithymic features were related to depressive symptoms; that alexithymia is a structure not-separate from depression. Therefore, our results support the state-phenomenon-nature of alexithymia.

On the other hand, it is essential to mention that some researchers found alexithymia and depression to be separate phenomena and they claimed that alexithymia is a trait phenomenon, a construct independent from depression [31], a personality trait associated with deficits in the cognitive processing and regulation of affects [32] or provide findings that lend support for both absolute and relative stability of alexithymia [33].

The relationship between hostility and depression has been under discussion for quite a long time. In the early twenties' Austrian psychiatrist Sigmund Freud proposed the classical psychoanalytic perspective that depression (or 'melancholia') arouses when hostility is directed towards oneself's - as a reaction to an interpersonal loss [34], [35]. Riley et al [36] proposed that severity of depression was positively associated with levels of hostility in depressed patients. Alleviating of depressive symptoms was related to reduction of hostility. Fava et al came to the conclusion that a decrease in hostility following antidepressant treatment is related to a reduction in depressive symptoms [37]. In our study, in a sample of patients with depression, somatic illnesses and healthy individuals, hostility correlated positively with depression, supporting the depression-hostility relationship. What is more, both introverted and extraverted hostility were positively related to the levels of depression. This finding overcomes the classical Freudian aspect, which regards depression as the result to hostility directed exclusively toward oneself. According to our results, depressive feelings come along with anger towards oneself, as well as with anger towards others. The psychodynamic approach, trying to explain these relationships, suggests several models, such as the reactions to separation, the organization of certain personalities, the sociocultural prohibition of aggressive responses, which, at least in part, account for the hostility-depression relationship [38].

Possible connection between alexithymia and hostility is an issue that is, so far, less examined than the previous ones. Calikuu et al [39] found a positive correlation between anger and alexithymia scores $(r=.49, \mathrm{p}<.05)$ in patients with psychogenic excoriation. Spitzera et al [40] accept the relationship between alexithymia and hostility, and Helmes et al [41], after studing three nonclinical populations in Australia and Canada, support the association of alexithymia with emotional inhibition. We investigated the relationship between hostility and alexithymia in a population consisting of depressive patients, somatic patients and healthy people and came to the conclusion that this relationship is statistically significant. We believe that the emotional deficits of alexithymia, the difficulty in understanding their own and others' people feelings, and the difficulty in expressing their feelings, make it difficult for alexithymic people to cope with others. Living with people whose intensions and desires are incomprehensible to them, make them feel at a loss, and, sometimes, at danger. This awkward situation, feeling unable and vulnerable, along with their incapacity to verbalize their internal world, can trigger hostility.

In our study, no personality traits were tested among the participants, nor were scales used to examine chronic pain, fatigue or general functioning. These features may interfere with somatic illnesses, as well as with depression, alexithymia and hostility.

\section{REFERENCES}

[1] Sifneos, P.E., 1972. Short-term Psychotherapy and Emotional Crisis. Cambridge, Harvard University Press.

[2] Nemiah, J.C., Freyberger, H., Sifneos, P.E., 1976. Alexithymia: a view of the psychosomatic process. In: Hill OW, editor. Modern trends in psychosomatic medicine, Vol 3. London: Butterworths, pp. 430-9. [3] Salminen, J.K., Saarijarvi, S., Aarela, E, 1995. Two decades of alexithymia. J Psychosom Res, 39:803-7.

[4] Sifneos, P.E., 2000. Alexithymia, clinical issues, politics, and crime. Psychother Psychosom, 69:113-6.

[5] Taylor, G.J., 1984. Alexithymia: Concept, Measurement and Implications for Treatment. Am. J. Psychiatry, 141:6, 725-731.

[6] Foulds, G.A., 1965. Personality and Personal Illness. London, Tavistock. 24. 
[7] Angelopoulos, N.V., Drosos, A.A.., Moutsopoulos, H.M., 2001. Psychiatric Symptoms Associated with Scleroderma. Psychotherapy and Psychosomatics 2001; Vol. 70, No. 3

[8] Beck, A., Ward, C., Mendelson, M., Mock, J., Erbauch, J., 1961. An inventory for measuring depression. Archives of General Psychiatry, 4, 561-571.

[9] Beck, A.T., Beamesderfer, A.,1974. Assessment of depression: The depression inventory. Psychological measurements of psychopharmacology. In P. Pichot (Ed.), Modern Problems in Pharmacopsychiatry. Karger. [10] Donias, S., Demertzis, J., 1983a. Measure of depression in greek

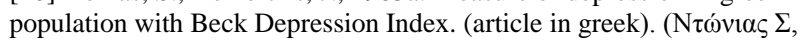

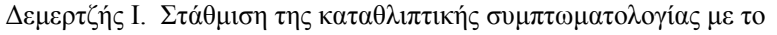

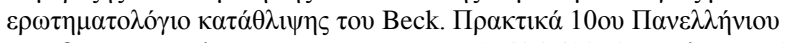

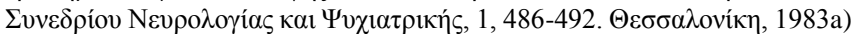
[11] Donias, S., Demertzis, J., 1983b. Measure of depression in psychiatric

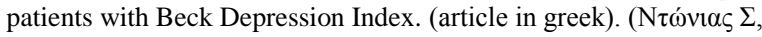

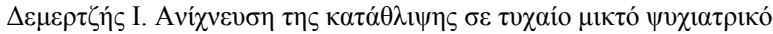

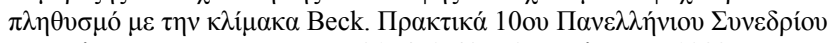

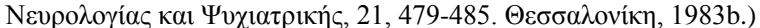
[12] Bagby, R.M., Parker, J.D.A., Taylor, G.J.,1994a. The Twenty-Item Toronto Alexithymia Scale-I. Item selection and cross-validation of the factor structure. J Psychosom Res, 38:23-32.

[13] Bagby, R.M., Taylor, G.J., Parker, J.D.A., 1994b. The Twenty-Item Toronto Alexithymia Scale-II. Convergent, discriminant, and concurrent validity. J Psychosom Res, 38:33-40.

[14] Bagby, M., Taylor, G., Parker, J., 1992. The revised Twenty-Item Toronto Alexithymia Scale: Some reliability, validity and normative data. Psychotherapy and Psychosomatics, 57:34-41.

[15] Taylor, G.J., Bagby, R.M., Ryan, D.P., Parker, J.D.A., 1990. Validation of the alexithymia construct: a measurement-based approach. Can J Psychiatry, 35:290-7.

[16] Taylor, G.J., Bagby, R.M., Ryan, D.P., Parker, J.D.A., Doody, K., Keefe, P., 1988. Criterion validity of the Toronto Alexithymia Scale. Psychosom Med, 50:500-9.

[17] Tsaousis I, Taylor G, Quilty L, Georgiades S, Stavrogiannopoulos M, Bagby RM (2010) Validation of a Greek adaptation of the 20-item Toronto Alexithymia Scale. Compr Psychiatry, Jul-Aug;51(4):443-8.

[18] Caine, T.M., Foulds, G.A., Hope, K., 1967. Manual of the Hostility and Direction of Hostility Questionnaire. London, University of London Press.

[19] McPherson, F.M., 1988. A note on the female norms of the HDHQ. Br J Clin Psychol, 27, 263-264.

[20] Economou, M., Angelopoulos, N.V., 1989. Dysthymic symptoms, hostility and scholastic achievement in a group of high school students. Educ Psychol, 9, 331-337.

[21] Lyketsos, G.S., Blackburn, I.M., Tsiantis, J., 1988. The movement of hostility during recovery from depression. Psychol Med, 8, 145-149.

[22] Angelopoulos, N.V., Tsivaridou, D., Nikolaou, N., Pavlidis, N., 1995. Mental symptoms, hostility features and stressful life events in people with cancer. Acta Psychiatr Scand, 92, 44-50.

[23] Norusis, M., 1993. SPSS for Windows. Users Guide, Release 6.0 Chicago, SPSS Inc, 1993.

[24] Hintikka, J., Honkalampi, K., Lehtonen, J., Viinamaki, H., 2001. Are alexithymia and depression distinct or overlapping constructs?: a study in a general population. Compr Psychiatry, 42(3):234-9.

[25] Honkalampi, K., Koivumaa-Honkanen, H., Antikainen, R., Haatainen, K., Hintikka, J., Viinamaki, H., 2004. Relationships among alexithymia, adverse childhood experiences, sociodemographic variables, and actual mood disorder: a 2-year clinical follow-up study of patients with major depressive disorder. Psychosomatics, 45(3):197-204.

[26] Gulec, H., Sayar, K., Ozkorumak, E., 2005. Somatic symptoms of depression. Turk Psikiyatri Derg, 16(2):90-6.

[27] Nakao, M., Kashiwagi, M., Yano, E., 2005. Alexithymia and grief reactions in bereaved Japanese women. Death Stud, 29(5):423-33.

[28] Saarijarvi, S., Salminen, J.K., Toikka, T.B., 2001. Alexithymia and depression: a 1-year follow-up study in outpatients with major depression. J Psychosom Res, 51(6):729-33.

[29] Honkalampi, K., Koivumaa-Honkanen, H., Tanskanen, A., Hintikka, J., Lehtonen, J., Viinamaki, H., 2001a. Why do alexithymic features appear to be stable? A 12-month follow-up study of a general population. Psychother Psychosom, 70(5):247-53.

[30] Gunzelmann, T., Kupfer, J., Brahler, E., 2002. Alexithymia in the elderly general population. Compr Psychiatry, 43(1):74-80.

[31] Luminet, O., Bagby, R.M., Taylor, G.J., 2001. An evaluation of the absolute and relative stability of alexithymia in patients with major depression. Psychother Psychosom, 70(5):254-60.

[32] Troisi, A., D'Argenio, A., Peracchio, F., Petti, P., 2001. Insecure attachment and alexithymia in young men with mood symptoms. J Nerv Ment Dis, 189(5):311-6.
[33] Picardi, A., Toni, A., Caroppo, E., 2005. Stability of alexithymia and its relationships with the 'big five' factors, temperament, character, and attachment style. Psychother Psychosom., 74(6):371-8.

[34] Freud, S., 1984. "Mourning and Melancholia". in Richards A (ed.). 11.On Metapsychology: The Theory of Psycholoanalysis. Aylesbury, Bucks: Pelican. pp. 245-69.

[35] Carhart-Harris, R.L., Mayberg, H.S., Malizia, A.L., Nutt, D., 2008.

Mourning and melancholia revisited: Correspondences between principles of Freudian metapsychology and empirical findings in neuropsychiatry. Annals of General Psychiatry, Jul 24;7:9. doi: 10.1186/1744-859X-7-9.

[36] Riley, W., Treiber, F., Woods, M.G., 1989. Anger and Hostility in Depression. The Journal of Nervous and Mental Disease, Vol 177 - Issue 11. [37] O'Sullivan, R., Rosenbaum, J.F., 1996. Hostility changes following antidepressant treatment: Relationship to stress and negative thinking. Journal of Psychiatric Research, 30(6): 459-467.

[38] Braconnier A, Jeanneau A., 1997. Anxiety, aggression, agitation and depression: psychopathologic aspects. Encephale, Jun;23 Spec No 3:43-7. [39] Calikuu, C., Yuecel, B., Polat, A., Baykal, C., 2002. Expression of anger and alexithymia in patients with psychogenic excoriation: a preliminary report. The International Journal of Psychiatry in Medicine, Vol 32, Number 4.

[40] Spitzera, C., Siebel-Jürgesb, U., Barnowa, S., Grabea, H.J., Freybergera, H.J., 2005. Alexithymia and Interpersonal Problems. Psychother Psychosom, 74:240-246.

[41] Helmes, McNeill, P., Holden, R.R., Jackson, C., 2009. The construct of alexithymia: associations with defense mechanisms. Journal of Clinical Psychology, 64(3): 318 - 331 . 